\title{
O barroco na escrita de Clarice Lispector
}

\author{
The baroque in Clarice Lispector's writing
}

\section{El barroco en la escritura de Clarice Lispector}

\author{
iD@ Maria Stella Galvão Santos \\ Universidade Federal do Rio Grande do Norte (UFRN), Natal, Rio Grande do Norte, Brasil. \\ E-mail: stellag@uol.com.br
}

\begin{abstract}
Resumo: A obra de Clarice Lispector encontra-se impregnada por elementos barrocos ao longo da escritura de vários de seus romances, como têm demonstrado alguns estudos no âmbito da teoria literária. Características peculiares à escritura da ficção clariceana a inscreveriam na linha de escritores brasileiros contemporâneos em cuja obra o barroco desponta de maneira inequívoca. Digressões, antíteses, paradoxos, estranhamentos são traços estilísticos do barroco na literatura que podemos identificar das obras dessa escritora. Assim, os problemas gerais da linguagem, da arte, da existência e da morte, que coexistem na estética barroca, conferem um caráter ensaístico em várias de suas obras, como anuncia a própria Clarice em Água Viva. “E quando estranho a palavra, é aí que ela alcança o sentido. E quando estranho a vida aí é que começa a vida." (LISPECTOR, 1980, p. 85).
\end{abstract}

Palavras-chave: Literatura. Barroco. Clarice Lispector.

Abstract: Clarice Lispector's work is impregnated by baroque elements throughout the writing of several of her novels, as some studies in the field of literary theory have shown. Lispector can be included in the line of contemporary Brazilian writers in whose work the Baroque appears unequivocally, due to the peculiar characteristics of hers writing. Digressions, antitheses, paradoxes, strangeness are stylistic features of the Baroque in literature that we can trace from this writer's works. Thus, the general problems of language, art, existence and death, which 
coexist in Baroque aesthetics, give an essayistic character in several of hers works, as announced by Clarice in Água Viva. "And when the word is strange, that s where it gets its meaning. And when life is strange, life begins there." (LISPECTOR, 1980, p. 85).

Keywords: Literature. Baroque. Clarice Lispector.

Resumen: La obra de Clarice Lispector está impregnada de elementos barrocos a lo largo de la escritura de varias de sus novelas, como han demostrado algunos estudios en el campo de la teoría literaria. Características propias de la escritura de la ficción de Lispector la inscribirían en la línea de los escritores brasileños contemporáneos en cuya obra emerge inequívocamente el barroco. Digresiones, antítesis, paradojas, extrañezas son rasgos estilísticos del barroco en la literatura que podemos rastrear en la obra de esta escritora. Así, los problemas generales del lenguaje, el arte, la existencia y la muerte, que conviven en la estética barroca, confieren un carácter ensayístico en varias de sus obras, como lo anuncia la autora en Água Viva. "Y cuando la palabra es extraña, ahí es donde adquiere su significado. Y cuando la vida es extraña, la vida comienza ahí “. (LISPECTOR, 1980, p. 85).

Palabras clave: Literatura. Barroco. Clarice Lispector.

Submetido em 30 de agosto de 2020.

Aceito em 09 de outubro de 2020.

Publicado em 13 de setembro de 2021. 
O conjunto da obra de Clarice Lispector (1920-1977), no panorama da literatura brasileira da segunda metade do século XX, é considerado um dos mais singulares e expressivos da prosa nacional. Objeto de estudos consistentes no âmbito da teoria literária, as tramas urdidas pela ucraniana, naturalizada brasileira, é uma das que mais ensejam leituras múltiplas. Neste artigo, abordamos alguns apontamentos que descrevem os traços barrocos na ficção clariceana e a inscrevem, conforme Solange Oliveira (1984), na linha de escritores brasileiros contemporâneos em cuja obra a estética do século XVII desponta de maneira inequívoca. Essa autora situa Clarice, por esta característica, junto à prosa de Jorge de Lima, Guimarães Rosa e Murilo Mendes.

Os temas da extensa obra literária da autora são atravessados pelos seguintes aspectos característicos da literatura barroca: "a dúvida sistemática ao conhecimento, a visão da verdade como algo que sempre inclui o seu oposto, a preocupação com a precariedade da aparência são [...] elementos temáticos básicos de toda a poesia barroca europeia." (OLIVEIRA, 1984, p. 113). Incluem-se ainda o farto uso de paradoxos e as antíteses típicas do estilo adotado por Clarice, como o fazem grandes prosadores barrocos. Essa aproximação ocorreria de maneira grandiloquente em três dos seus romances: O lustre (1946), A cidade sitiada (1949), A maçã no escuro (1961). ${ }^{1}$

Segundo Olga de Sá, outra estudiosa do enlace barroco presente na obra clariceana, "os problemas gerais da linguagem, da arte, da existência e da morte (marcadamente presentes nas obras de inspiração barroca) provocam 'digressões' na escritura de Clarice, retardam a narrativa e lhe conferem um caráter ensaístico" (SÁ, 1984, p. 260). Trata-se de uma cosmovisão singular e diferenciada. "Não, nunca fui moderna. E acontece o seguinte: quando estranho uma pintura é aí que é pintura. E quando estranho a palavra é aí que ela alcança o sentido. E quando estranho a vida aí é que começa a vida." (LISPECTOR, 1980, p. 85). O estranhamento é mesmo um dos modos de contato escolhidos pela escritora para aproxi-

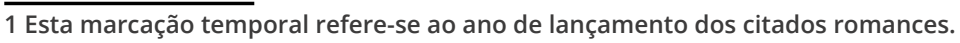


mar sua atividade artística, ora de uma experiência viva, real, ora inóspita, divagadora, como acentuam vários comentadores de sua obra. Sobre o conceito de estranhamento relacionado à construção ficcional e latente em toda a crítica literária desde Aristóteles, como detalha Oliveira (1984, p. 122), "indica um certo efeito estético, conseguido com vários artifícios, por meio dos quais a percepção, normalmente embotada pela familiaridade, é aguçada."

O lustre é narrado em terceira pessoa, sendo o narrador onisciente. Durante todo o livro, o foco prevalece sob a perspectiva de Virgínia, a protagonista. Acompanhamos seu amadurecimento, desde sua vida infantil, na granja onde nasceu, até firmar-se, no presente da narrativa, na solidão da cidade. Essa apresentação se dá, porém, pela descrição do que cerca Virgínia, o que a influencia - tanto objetos, a exemplo do lustre do título, como pessoas próximas a ela, seu irmão que ela seguia como a um líder.

Agradecia-lhe com uma alegria difícil, frágil e tensa, sentia em alguma coisa como o que não se vê de olhos fechados - mas o que não se vê de olhos fechados tem uma existência e uma força, como o escuro, como o escuro, como a ausência, compreendia-se ela assentindo, feroz e muda com a cabeça. (LISPECTOR, 1999, p. 44).

O romance, de acordo com a crítica literária Gilda de Mello e Souza (1989), que estudou certas particularidades da escrita da autora, é elaborado em torno de um tema central, da busca do sentido da vida, se acercando também às matrizes do desencontro e da incomunicabilidade humana. A análise foi publicada pelo jornal O Estado de S. Paulo em julho de 1946, em seguida ao lançamento do segundo romance da escritora. Posteriormente foi republicado, em 1989, na revista acadêmica 'Remate dos males'. Nesta análise, Lispector pertenceria ao grupo de romancistas que dá ênfase aos reflexos dos acontecimentos no interior de cada personagem, dissecando emoções, sentimentos, estados de alma e agonias do espírito. 
A escritora busca traduzir, desse modo, "não o que existe de simples e lógico no mundo, mas de complexo e contraditório. Em cada objeto vê, não o que o iguala a outros de suas espécies, mas o que o diferencia. Em cada ser, o que o torna único. Em cada emoção, o que a torna específica." (SOUZA, 1989, p. 171). Equivale dizer então que a autora fará o caminho inverso ao do aclaramento que, se espera, seja produzido pela linguagem. Um exemplo fornecido por Mello e Souza: Diante da palavra "mancha", surgem os possíveis atributos: grande, pequena, clara, escura, larga, esguia, todos eles definindo melhor a noção de mancha. Outro exemplo é o atributo do substantivo "água" nesta passagem do livro: "[...] viu uma pequena água correndo perto, mas o líquido estava cansado e morno, dava-lhe na boca sedenta uma impressão grossa em vez de picá-la com estremecimentos frios" (LISPECTOR, 1999, p. 245). Neste sentido, encontramos em Olga de Sá (1984) o seguinte comentário, calcado no texto de Gilda de Mello e Souza:

Pretendendo traduzir o que existe de complexo e contraditório no mundo, a romancista tem de violentar a lógica da linguagem [...]. Tal processo repercute na adjetivação, que não poderá ser objetiva, definidora, mas será antes subjetiva, para traduzir uma emoção mais rica. (SÁ, 1984, p. 36).

Um dos muitos modos de Clarice provocar o estranhamento é chamar a atenção para o caráter material da linguagem, mostrando que a palavra não revela: ela é. "Sem saber, repetia a si própria como numa oração perfeita: cal ferro areia silêncio e purificava-se nessa ausência de homem e de Deus." (LISPECTOR, 1999, p. 144). Em O lustre a luz é penumbrosa. A personagem central, Virgínia, vive presa, exilada das coisas, e erra sozinha no fundo desse instante penumbroso que é a sua vida, como nesta análise do romance: "O escuro aparece como prenúncio da atmosfera interiormente dominada pelo efeito da sombra; a atmosfera negativa, que o início do romance introduz, vai adensar-se num clima de mistério, desenrolando-se até a expressão trágica final." (SOUSA, 2000, p. 175). A introdução ao objeto que nomeia o romance é feita de 
repetições, recurso mnemônico de presença frequente na escrita com tintas barrocas de Clarice Lispector.

A sala. A sala cheia de pontos neutros. O cheiro de casa vazia. Mas o lustre! Havia o lustre. A grande aranha escandecia. Olhava-o imóvel, inquieta, parecia pressentir uma vida terrível. Aquela existência de gelo. Uma vez! Uma vez a um relance - o lustre se espargia em crisântemos e alegria. Outra vez - enquanto ela corria atravessando a sala - ele era uma casta semente. O lustre. Saía pulando sem olhar para trás. (LISPECTOR, 1999, p. 15).

A incorporação paulatina da influência dos traços barrocos junto à crítica literária desponta, conforme Coutinho (1976), no final do século XIX, como um desafio à historiografia literária que via as produções entre o período Renascentista e Neoclássico como uma arte degenerada. Para além de estética do "excesso", o Barroco se opôs ao racionalismo do Renascimento propondo a "[...] liberdade da irregularidade e da emoção" (COUTINHO, 1986, p. 92). Essa inter-relação entre parte da obra de uma das escritoras mais importantes da literatura brasileira e o movimento estético do barroco podem ser potencializados, a nosso ver, em sala de aula, produzindo uma forma atrativa de estimular a prática da escrita, relacionando literatura e estética, ainda que as referências na crítica literária brasileira sejam erráticas e escassas.

Na contramão da escassez de referências no romance contemporâneo, em artigo sobre o diálogo do Barroco com a contemporaneidade, Bylaardt (2018) afirma ser impossível enumerar as manifestações de arte no Brasil em que se pode sentir a alma barroca e suas dobras. "Poderíamos citar autores, obras, numa lista infinita como os caminhos de dobras, desdobras e redobras do barroco, que sempre aparecerá na próxima curva, na próxima dobra, outro artista, outra surpresa, outra linguagem que o espírito barroco sustenta". (BYLAARDT, 2018 , p. 166). O autor se inscreve entre aqueles que saúdam a estética barroca pela noção de excesso, desvelo ou acobertamento do real. "Pode-se pensar também que o diálogo da literatura contemporânea com o barroco tem a ver com essa ideia de vertigem, de desmesura." (idem, ibid). Constitui nítido traço barroco, por exemplo, a tentativa de 
ultrapassar os limites da linguagem por meio de paralelos sugestivos de efeitos próprios da escultura, da pintura, da música e mesmo do mobiliário. Em Clarice Lispector, a afinidade com os escritores barrocos da literatura mundial transparece na temática, na construção dos personagens e na estrutura de linguagem utilizada.

Benedito Nunes (1995, p. 84) constata que, na grande maioria das narrativas curtas de Clarice Lispector, há o que se pode chamar de "tensão conflitiva", ou seja, um episódio único será o responsável pela distensão da história, abrindo caminhos para o desnudamento do personagem diante da sua própria existência. Em alguns contos, essa "tensão conflitiva" se declara repentinamente e instaura um rompimento do personagem com o mundo. Em outros, vamos encontrar uma atmosfera de crise declarada, que não se resolve através de um ato, ao contrário, mantém-se firme do começo ao fim, seja na forma de aspiração ou devaneio, seja na forma de mal-entendido ou incompatibilidade entre as pessoas. Desse modo, assiste-se à propagação de uma atmosfera de estranheza diante das coisas, de conflitos de sentimentos e de uma consciência culposa. Ainda que seja uma característica notavelmente marcante nos contos, a descrição de Nunes pode extrapolar também para a prosa mais extensa da escritora.

A maçã no escuro conta a história de Martim, um homem que foge na noite, se refugia num hotel e depois numa fazenda, pois pensa ter matado a esposa. O corpo é o artífice da escritura de Clarice durante todo o romance. O ambiente é o das sensações, do pensamento, e aos leitores cabe construir o entendimento aos poucos. No livro no qual aborda a escritura clariceana, sob o subtítulo A travessia do oposto, Olga de Sá (1993) assim descreve uma passagem que reflete sobre o protagonista do romance:

Martim estava exausto e, por cansaço, numa visão balsâmica, refugiou-se nas "plantas grossas de seu terreno terciário". "Não ser" era vasta a noite de um homem. Esquecer os outros, encontrar um lugar de paz. Para encontrar este lugar, essa terra comum e solitária onde "apenas como cegos" nos apalpamos, era preciso um ato de aceitação. (SÁ, 1993, p. 112) 
Essa aceitação dá-se de maneira a reforçar os signos literários clariceanos, difusos e simultaneamente clarividentes: "Eu te aceito lugar de horror onde os gatos miam contentes, onde os anjos têm espaço para na noite bater asas de beleza, onde entranhas de muIher são o futuro filho e onde Deus impera na grave desordem da qual somos os felizes filhos." (LISPECTOR, 1998, p. 246). Segundo Sá, para Clarice esse é o lugar da escritura, que se defronta com o instinto de viver. Assim, Martim não fugiu ao seu destino. Será preso, não será, porém, será destruído. "Por direito de nascença, podemos ser o que somos e o cão, em nós, conhece o caminho." (idem, ibid, p. 247).

Em $O$ dorso do tigre, Benedito Nunes, leitor empedernido e crítico arguto da obra da escritora, afirma que um dos momentos decisivos da experiência de renovação de Martim no caminho da conquista de si mesmo é a descoberta e a tentativa de assimilação dos elementos sensíveis, brutos, penumbrosos, proliferantes e fortes da vida num curral de vacas. "Nessa atmosfera de entranhas palpitantes, Martim encontra sob forma de vida ativa, de matéria operante, que segue curso impassível, o sórdido, o fecal. Coisas afins se entremesclam em mistura hostil e repulsiva." (NUNES, 2009, p. 98).

Por nojo, o homem que repentinamente se tornara de novo abstrato como uma unha quis recuar; enxugou com o dorso da mão a boca seca como um médico diante de sua primeira ferida. No limiar do estábulo no entanto ele pareceu reconhecer a luz mortiça que se exalava do focinho dos bichos. Aquele homem já vira esse vapor de luz evolando-se de esgotos em certas madrugadas frias. E vira essa luz se emanar de lixo quente. Vira-a também como uma auréola em torno do amor de dois cachorros; e seu próprio hálito era essa mesma luz. (LISPECTOR, 1998, p. 104)

O paradoxo do personagem, melhor dizendo, dos personagens de Clarice Lispector é base, estofo, ferramenta, para o acesso dos leitores à dimensão secreta e existencial desses indivíduos retratados em sua crueza e distanciamento pela escritora. Segundo 
Nunes (2009), romances como O lustre e $A$ maçã no escuro permitem aos leitores acessar a dimensão subjetiva dos protagonistas dissecados até o limite de uma realidade profunda, impessoal e transcendente. "Podemos afirmar que o que interessa a Clarice Lispector não são os indivíduos em si, mas a paixão que os domina, a inquietação que os conduz, a existência que os subjuga." (NUNES, 2009, p. 116).

A estreita ligação entre os objetos e os personagens está relacionada à experiência vital deles na escrita da autora. 0 primado da percepção experimentado por eles gera um prolongamento das sensações. É nessa atmosfera de traços reflexivos que vai sendo exposto o mal-estar que existe nas diversas esferas de relacionamentos sociais: "no casamento, nas categorias diversas que compõem a família, no convívio problemático com pessoas distintas, e, principalmente, no ser humano solitário em busca do entendimento acerca de sua existência". (TEIXEIRA, 2010, p. 110). Como no encontro da narrativa com a fruta do título: A maçã pode ser tomada como símbolo da fé que serve de sustentáculo à esperança em meio à escuridão que representa a dúvida da humanidade. Mais barroco impossível. "Torna-se legítimo falar de narrativa barroca sempre que se considere um modelo, uma matriz, sobre a qual apontar desvios, exageros, distorções barrocas." (CHIAMPI, 1998 , p. 82). São características desta narrativa uma forte predileção por figuras como "o hipérbato, a perífrase, o metaforismo amaneirado" (idem, ibid, p. 83). Assim, voltemos à apoteose da saga de Martim: "Em nome de Deus, eu espero que vocês saibam o que estão fazendo. Porque eu, meu filho, eu só tenho fome. E esse modo instável de pegar no escuro uma maçã - sem que ela caia." (LISPECTOR, 1998, p. 334).

Finalmente, abordamos o terceiro livro da nossa 'trilogia barroca clariceana', A cidade sitiada, um dos mais estranhos romances de Clarice Lispector, segundo Sá (1993), e o único que teve uma segunda edição revisada e corrigida pela autora, em 1964. Por ocasião do lançamento de $A$ cidade sitiada, em 1949, o crítico e ensaísta paulista Sergio Milliet "denuncia a preocupação da joia-rara, o 
preciosismo, o rococó, a forma estratificada em fórmula" (SÁ apud MILLIET, 1993, p. 33). Em contrapartida, ainda conforme Olga de Sá (1993), o crítico literário e romancista Assis Brasil avaliou positivamente o romance e observou que ele se inscreve, na produção da escritora, "como o formalmente mais bem realizado", fato que atribui ao amadurecimento ao longo do intervalo entre o lançamento de $A$ cidade sitiada e a obra predecessora, O lustre, três anos antes. (SÁ apud ASSIS BRASIL, 1993, p. 34).

A história se passa na década de 1920 em um subúrbio onde vive a jovem Lucrécia Neves. Inconformada com a mesmice de um ambiente sem futuro, a personagem está dividida entre a vila-refúgio de origem e os sonhos da metrópole. Mas a inquietação da moça não vai além disso. "Lucrécia Neves talvez quisesse exprimi-lo, imitando com o pensamento o vento que bate portas - mas faltava-Ihe o nome das coisas" (LISPECTOR, 1992, p. 49). Seu modo de apreensão do real se dá pelo olhar, que não chega a se transformar em linguagem, em palavra. Lucrécia não vive, espia a vida. É seu modo sitiado de ser.

Só ela ainda estava consciente demais para começar o disfarce, o vento entre os sobrados apressava-a. Enquanto se descalçava forçava mesmo a confusão do quarto e da rua, de onde tiraria a própria forma. Nada, porém, a empurrara ainda para a realidade do que estava sucedendo. No compartimento sombrio a claridade era o buraco da fechadura. (LISPECTOR, 1992, p. 30)

Como relata o crítico Benedito Nunes (1989), A cidade sitiada reúne as experiências da personagem principal em um subúrbio em crescimento. São Geraldo é um subúrbio em crescimento na década de 1920. Tais mudanças se refletem nos habitantes, se associam à experiência interior de Lucrécia Neves, a protagonista do romance, que leva uma vida, por assim dizer, dupla. "Mocinha em busca de bom partido que a leve dali, ela passeia seu tédio pela cidade caminhando, de devaneio em devaneio, e nutrindo secretamente a esperança de libertar-se dos muros imaginários que si- 
tiam São Geraldo." (NUNES, 1989, p. 32). A angústia persegue Lucrécia na fase de busca de um estratagema para escapar da vida comezinha.
É que não podia suportar aquela muda existência que estava sempre acima dela, a sala, a cidade, o alto grau a que chegavam as coisas sobre a prateleira, o passarinho seco prestes a voar empalhado pela casa, a altura da torre da usina, tanto intolerá- vel equilíbrio - que só um cavalo sabia exprimir em cólera sobre as patas. (LISPECTOR, 1992, p. 59).

Na visão de Olga de Sá (1993), trata-se de uma personagem que busca evadir-se do subúrbio de São Geraldo, que progride e se civiliza lentamente, e onde as transformações se apresentam de forma que uma mudança se contrapõe a seu oposto.

\begin{abstract}
O termo subúrbio é usado não no sentido mais comum de "imediações ou cercanias de uma cidade", mas significando "povoação". Subúrbio traz embutida a palavra urbe = cidade, e ressoa em suburbano, isto é, de mau gosto. A transformação do subúrbio em cidade apresenta-se "em enigma", porque as coisas aparecem misturadas, "centaurizadas", metade homem/metade cavalo, civilização/campo, luz/sombra, seco/úmido, fora/dentro, superfície/mistério (SÁ, 1993, p. 35)
\end{abstract}

Ela observa ainda que as personagens deste livro têm traços que sugerem paródias de personagens de outras obras de Clarice Lispector, ou caricaturados em relação ao que deles normalmente se espera. Nesta perspectiva, podemos situar o comentário do crítico literário Antonio Candido, quando celebrou o aparecimento da nova escritora, ainda na década de 1940. “Clarice Lispector aceita a provocação das coisas à sua sensibilidade e procurar criar um mundo partindo das suas emoções, da sua própria capacidade de interpretação. A meta é, evidente, buscar o sentido da vida, penetrar no mistério que cerca o homem". (CANDIDO, 1970, p. 128). 


\section{Considerações finais}

Assim como os poetas barrocos, Clarice Lispector evidencia o gosto por metáforas nas quais se explora a surpresa do que escapa à compreensão, dos elementos implicitamente comparados: a verborragia dos personagens está presente nos silêncios ou nas sugestões vocabulares escolhidas pela autora, nas interrogações, no uso de palavras deslocadas do seu sentido usual, nas ausências de vírgulas e excessivos pontos finais. As narrativas da escritora obrigam-nos a uma reflexão em torno da linguagem literária e dos mecanismos de representação da realidade, sobretudo em torno da polifonia encontrada em seu discurso ficcional.

Os personagens, "premidos pela grande inquietação que os aguilhoa", como afirma Benedito Nunes (2009, p. 126), tentam deixar a esfera do inautêntico, do caricatural, em uma trilha em busca de si mesmos, mas a língua atua em sentido oposto à clareza e comunicação fluida. Inexiste, neste mundo ficcional muito particular, uma hierarquia em estado pleno, senão a que é marcada pela provisoriedade. É pelo jogo das antíteses e dos ardis de consciência que se movimentam as personas engendradas pela prosa, demasiadamente tensa e simbólica, de Lispector. Na verdade, os dois fracassos, o da existência e o da linguagem, apresentam-se intimamente associados e contribuem para lançar luzes ao que Nunes (idem, p. 132) chama de "a dialética interna do mundo imaginário de Clarice Lispector."

A inovação operada por Clarice, como demonstra uma enorme quantidade de estudos que segue esquadrinhando sua obra, organiza-se numa narrativa fragmentada, desinteressada do enredo factual, alicerçada no fluxo de consciência. Solange Oliveira, uma das autoras a destacar, preliminarmente, o viés claro ou tortuosamente barroco nas obras de Clarice Lispector, responde ao questionamento sobre em benefício do quê se dá a rarefação da fabulação, da escrita corrente e linear nos romances da escritora. Ela responde: "[...] principalmente em benefício da densidade 
metafísica da pesquisa do tempo. Os fatos são insignificantes, no mais exato sentido etimológico." (OLIVEIRA, 1984, p. 263).

Chega-se, portanto, à constatação de que há elementos suficientes para dar sustentação à hipótese levantada neste trabalho: há traços inequívocos da estética barroca literária nos romances de Clarice Lispector, especialmente nos três romances que se seguiram ao relato ficcional que marcou o ingresso da escritora no panteão literário brasileiro. Clarice aprofunda o tempo no âmago dos personagens, investe na averiguação sistemática de suas interioridades e promove uma travessia, balizada pelo acaso e pelos estados de ânimo, nos cenários nos quais se movimentam. Pela ampulheta do fluir temporal passeiam os dias, os acontecimentos, o pensamento, contrariando a mais remota ideia de fixidez de histórias que não primam, necessariamente, pelo fluxo contínuo do relato. Ao contrário. O leitor percebe com algum esforço que está diante de uma estrutura textual baseada na fugacidade do tempo, na instabilidade das consciências, na desintegração da narrativa linear. Os conflitos se instalam na experiência existencial de cada um deles, onde reaparecem as recordações e percepções fugidias misturadas a inquietações metafísicas. Clarice Lispector, em sua faceta barroca, é uma legítima representante da expressão desenfreada de pensamentos e emoções, fatores primordiais da criação literária. Ao finalizar, portanto, nos cabe dizer que esta pesquisa evidentemente não se esgota em um artigo, mas mantém aberta a senda para novas abordagens do tema sob o prisma da estética barroca.

\title{
Referências
}

\author{
BYLAARDT, Cid Ottoni. O barroco e seu diálogo com a contemporanei- \\ dade. Revista Entrelaces. v. 1, n. 12, p. 162-171, abr./jun. 2018. \\ CANDIDO, Antonio. No raiar de Clarice Lispector [1943]. In: Vários es- \\ critos. São Paulo: Duas Cidades, 1970.
}


CHIAMPI, Irlemar. Barroco e modernidade. São Paulo: Perspectiva, FAPESP, 1998.

COUTINHO, Afrânio. Introdução à literatura no Brasil. Rio de Janeiro: Civilização Brasileira, 1986.

LISPECTOR, Clarice. Água viva. Rio de Janeiro: Nova Fronteira, 1980.

LISPECTOR, Clarice. A cidade sitiada. Rio de Janeiro: Rocco, 1992.

LISPECTOR, Clarice. A maçã no escuro. Rio de Janeiro: Rocco, 1998.

LISPECTOR, Clarice. O lustre. Rio de Janeiro: Rocco, 1999.

NUNES, Benedito. O drama da linguagem. 2. ed. São Paulo: Ática, 1995.

NUNES, Benedito. O mundo imaginário de Clarice Lispector. In: O dorso do tigre. São Paulo: Editora 34, 2009 (1 ${ }^{\text {a }}$ edição 1969), p. 93-134.

OLIVEIRA, Solange R. Aspectos barrocos do romance de Clarice Lispector. 0 eixo e a roda, Revista de Literatura Brasileira. v. 2, N. 2, p. 113-123, Jun.1984.

SÁ, Olga de. Clarice Lispector: Processos Criativos. Revista Iberoamericana, v. L, n. 126, Enero-Marzo 1984.

SÁ, Olga de. Clarice Lispector: a travessia do oposto. São Paulo: Annablume, 1993.

SOUSA, Carlos Mendes. Clarice Lispector. Figuras da escrita. Braga: Universidade do Minho (Coleção Poliedro), 2000.

SOUZA, Gilda de Mello. O Lustre. Remate de males, Campinas, n. 9, p. 171-175, 1989.

TEIXEIRA, Mona Lisa B. Imagens da infância na obra de Clarice Lispector. Tese (Doutorado em Letras) Faculdade de Filosofia, Letras e Ciências Humanas da Universidade de São Paulo (USP). São Paulo, 2010. 